\title{
Prevalenceof Intestinal Parasites and Associated Factors Among Food Handlers Working in Food and Drink Establishments at Mizan-aman Town, Southwest Ethiopia, 2018, Community Based Study
}

Aklilu Mamo Dachew ( $\nabla$ abigiaakmamo@gmail.com )

Mizan-Tepi University https://orcid.org/0000-0003-3862-695X

Girma Mamo Zegene

mizan Aman health science collage

Esrael Derekiab Shanab

Aman Foundation

Mesenbet Muluken Endalew

Mizan Aman Health science collage

Samuel Sahle Kebede

Mizan Tepi Unversity

\section{Research}

Keywords: Intestinal parasites, Food handlers, Food and drink establishments

Posted Date: January 23rd, 2021

DOI: https://doi.org/10.21203/rs.3.rs-152009/v1

License: (c) (i) This work is licensed under a Creative Commons Attribution 4.0 International License. Read Full License 


\section{Abstract}

Background: Food borne diseases has remained a major global public health issue with substantial morbidity and mortality associated with the consumption of contaminated food staffs. Parasitic infection is among the major disease especially in developing countries and sub-Saharan countries.

Objective:-This study was to determine the prevalence of intestinal parasites and associated factors among food handlers working in food and drink establishments at Mizan Aman town southwest Ethiopia.

Method:-A community based cross sectional study was conducted in Mizan Aman town. A total of 418 food handlers from randomly selected 209 foods and drink establishments were interviewed and finally stool samples were taken. Parasitological assessment was performed by qualified laboratory technologists using the physiological saline for wet mount and zinc sulphate and formol ether concentration techniques were used. Data were analyzed using statistical SPSS version 21 . $P \leq 0.05$ was taken as statistically significant

Result: The overall prevalence of intestinal parasites in Mizan Aman town was $26.1 \%$.work experience $>10$ years (AOR=0.52,95\% Cl ;2.430,5.012), the food handlers who did not trimmed their finger, $(A O R=1.89,95 \% \mathrm{Cl}: 1.01,3.960)$ and using common knife for cutting raw meat and other foods ( $A O R=0.57,95 \% \mathrm{Cl}: 3.61,5.54)$ were factors associated with parasitic infections.

Conclusion: The magnitude of intestinal parasite in mizan aman town is high and work experience, finger trimming status, and using common knife for cutting raw meat and other foods were factors associated with the parasitic infections

\section{Background}

For several years, food borne diseases remain a major global public health issue with substantial morbidity and mortality associated with the consumption of contaminated food staffs ([1],[2]). According to WHO, food handling personnel play significant role in ensuring food safety throughout the chain of food production. Therefore, to reduce food borne illnesses, it is crucial to raise the knowledge and quality of practices of food handlers. However, several factors contribute to the spread of food borne outbreaks by food service workers [3].Parasite is an organism that is entirely dependent on another organism, referred to as its host, for all or part of its life cycle and metabolic requirements[4].

Parasitic infection is among the major disease in the world especially developing countries and sub-Saharan countries [5]. According to World Health Organization (WHO) estimation, 3.5 billion people worldwide were infected with intestinal parasites and nearly greater than $\mathbf{4 5 0}$ million of them developed disease due to intestinal parasites, the majority were children [6]. Many studies reported the presence of relatively high prevalence rates of major protozoan and helminthes infections in tropical countries, where parasitic diseases remain among the heaviest and serious health problems [7], [8].

The cause for high distribution of parasites were reported as a result of specific climate of the regions, local customs, age, job, educational level of people ,attitude of peoples on parasitic infection and the use of human and animal fertilizers in agriculture and floriculture [9]. Due to geographical location, climate, and cultural and biological characteristics, there is a suitable atmosphere for the parasitic infestations in Ethiopia [10].The absence of clean and safe water, high population density, lack of proper disposal of waste, noncompliance with health standards, lack of adequate washing of vegetables, lack of washing hands before and after toilet and feeding of uncooked meat and drinking un boiled(non- pasteurized) milk lead to high prevalence of intestinal parasites[11]. Moreover, where poor environmental sanitation, poor personal hygiene and low level of education were among the reasons [12].As study reports, there was different types of parasites and different level of infection in different parts of Ethiopia.[5], [13].Ethiopian ministry of health prioritized parasitic disease as neglected tropical disease (NTDS) [14]. Some of negative consequences of parasitic infections reported were malnutrition, 
stunted growth, anemia and cognitive impairment (17). Food-handlers working in restaurants, and cafeteria harbor and excrete intestinal parasites that may contaminate food and serve as source of food-borne infections [10].

To prevent, food borne illnesses, all food handlers are required to practice food hygiene and safety activities. Food hygiene is the set of basic principles employed in the systematic control of the environmental conditions during production, packaging, delivery/transportation, storage, processing, and preparation, selling and serving of food in such a manner as to ensure that food is safe to consume. However, inappropriate and inconsistent food hygiene and safety activities can cause a health threat in developing countries due to difficulties in securing optimal hygienic food handling practices [15], [16].

Globally 819 million people were infected with Ascaris lumbricoides (A. lumbricoides), 464.6 million people were infected with Trichuris trichiura ,438.9 million people were infected with hookworm,500 million people were infected with Entamoeba histolytica (E. histolytica) and 2.8 million people were infected with Giardia lamblia[12].

Parasitic diseases which are one of major diseases in the world especially in developing countries [5]. Many studies discovered that parasitic infections cause so many diseases [9].They cause mental retardation, abdominal cramp, nausea, bloating, anorexia, anemia, stunt growth, malnutrion and diminished work capacity (17). As WHO report, about one third population in developed countries were infected by intestinal parasites whereas report for developing country indicates five times higher than developed countries [17]. In developing countries, up to $70 \%$ of cases of diarrheal disease are associated with the consumption of contaminated food. On the other hand, the growth of urbanization and transportation increased the number of peoples who use hotels and cafeterias for feeding and drinking services [16].

Because of food prepared in large quantities is more likely to be contaminated, there is a greater potential for the occurrence of food borne disease outbreaks if basic sanitary practices are not maintained[16].Ethiopia is one of developing countries whose majority of population is affected by intestinal parasites [2], [18].

Food handlers play a great role in communication of parasitic infection [17]. In developing countries as Ethiopia food handlers are hired without any screening for intestinal infections[19].

Asymptomatic patients with parasitic infections were considered to be hazardous to the society because such food handlers routinely exercise their jobs without giving due attention for the transmission of infections. As a result, intestinal parasites can be transmitted to consumers directly or indirectly through food, water, and fingers from food handlers[17].

Studies showed that, the prevalence of parasitic infection was found to be from $2 \%$ to $61 \%$ [20],[17].The parasitic infection and transmission was found to be associated with age ,job position, year of service, educational status, hand washing practice after toilet, hand washing before and after serving, trimming finger nails, wearing cup , gown, training and medical checkup[10]. Therefore this study was aimed to assess the prevalence of intestinal parasites and associated factors among food handlers working in food and drink establishments at mizan-aman town. The study will help in initiation of raising the quality service provision to the food and drink establishments' owners. In addition, it will also play a great role for achievement of national growth and transformation plan, by helping in reducing morbidity and mortality in relation to unsafe food and drink services provision. Moreover, this study will also be a baseline for researchers, and other concerned bodies whether governmental or nongovernmental bodies

\section{Methods}

\section{Study area and period}

The study was conducted in Bench Maji zone at Mizan Aman town in SNNP Regional State which is located $561 \mathrm{~km}$ from Addis Ababa in south west direction, the town has total population of 57,537 , of these 30,379 were males and 27,158 
females (CSA, 2007). There were 135 and 189 food and drink establishments within the town. Totally 324 food and drink establishments were registered by Mizan Aman town Trade and Industry Office in 2018.

The study was conducted from March 1/2018- April 30/ 2018 E.C.

\section{Study design}

A community based cross-sectional study was conducted in mizan aman town .

\section{Source Population}

All food handlers working in food and drink establishments in Mizan Aman town

\section{Study population}

All randomly selected food handlers working in each selected food and drink establishments in Mizan Aman town

\section{Sample size}

Sample size was calculated by using a single population proportion formula assuming $95 \%$ confidence interval, $5 \%$ margin of error and prevalence of intestinal parasites $44.1 \%$ among food handlers' at Jimma zone Yebu town was taken as proportion [12].

Therefore, Where $\mathrm{P}=0.44 \% \mathrm{Z}=95 \% \mathrm{~d}=5 \%$ ) and $10 \%$ non-response rate.

$n=\frac{z\left(\frac{\alpha}{2}\right) 2 * P(1-p)}{d^{2}}=\mathbf{4 1 8}$

\section{Sampling techniques (see figure 1 below)}

\section{Data collection tools and procedures}

\section{Data and stool collection tools}

Data collection materials were adapted from other related researches and translated to Amharic and back to English by experts.pre test was done on $5 \%$ of calculated sample size in Tepi town and questionnaires were modified accordingly.

\section{Data and stool collection procedures}

All participants were informed about the purpose of the study and after getting their willingness, interview was made, about a paean size of the stool samples were collected from each selected food handlers after interview. Collected stool specimens were transported by cold box to Mizan Aman Health Science College laboratory and Parasitological 
assessment was performed by qualified laboratory technologists using both the physiological saline and iodine wet mount and Formol ether concentration techniques as described on the standard. Dispensing the saline preferably from a small dropper bottle which can be closed when not in use to avoid contaminating the reagent was done [12]. The direct saline wet mount was employed not to miss trophozoites of E. histolytica and G. lamblia. All of the parasites detected by direct saline wet mount were also detected by Formol ether concentration technique.

\section{Data and stool sample collectors}

Ten laboratory technicians were recruited for the data and stool sample collection after two days training .Five supervisors were also assigned to check data completeness on daily bases.

\section{Inclusion and exclusion criteria}

\section{Inclusion criteria}

All food handlers who were engaged in food preparation, serving and cleaning utensils during the study period were included.

\section{Exclusion criteria}

Food handlers with confirmed intestinal parasite infection and on treatment were excluded from this study

\section{Data analysis}

Data were coded and entered, in epi data version 3.1 and transported to SPSS version 21.0 for analysis purpose. Percentage and frequency distribution was performed. Bivariate analysis was done to check association between dependent and each independent variable. Variables having $p$-value $<0.25$ in the bivariate analysis were taken for multivariate logistic regression. Variables whose $p$-value $<0.05$ were considered as statistically significant

\section{Data quality management}

Supervisors and data collectors were trained focusing on the way of communication with participants and specimen handling.

Before the actual data collection pre test was done on $5 \%$ of sample size in Tepi town. data were checked for completeness, coded and entered into Epi-data 3.1 and exported to SPSS version 21.Similarly, stool sample quality also kept based on standards [22].

\subsection{Ethical considerations}

This research was conducted after getting approval from Mizan Aman Health Science College research and publication office. Permission was obtained from Mizan Aman town Trade and Industry Office. During data collection the aim of the study was communicated to the respondents and the food \& drink establishment owners after signing on the consent form

\subsection{Dissemination plan}


The finding of this study was presented to Mizan Aman Health Science College. The copies of the finding were given to Trade and Industry Office.Moreover, attempts will be made to publish reputable international journals.

\section{Results}

\subsection{Socio demographic characteristics}

A total of 418 food handlers participated in the study, but 19 of them refuse to participate, so the response rate was $95.4 \%$. Among 399 participants 203 (50.9\%) were female and 194(49.1\%) were male. Regarding the age of participants, majorities (48.6\%) were less than 20 years old and only $1 \%$ were 65 years and above. Majority $(54.4 \%)$ of the respondent's educational status was primary education (from grade 1-8) whereas only $4 \%$ of the study participants attended their education to university level. Two hundred thirty seven (59.4\%) sample's specific job in the establishment was waiter, but only $52(13 \%)$ sample's job was cleaner. Almost half (49.4\%) of the respondents work experience in the food and drinking establishment was below 1 year, and only $1 \%$ of the study participants have above 10 year work experience. Only $6.8 \%$ of the study samples have training on food preparation and hygiene. $13.7 \%$ of them were infected by intestinal parasites which were the highest proportion from total prevalence of parasites. Only $27(6.8 \%)$ food handlers had training in food safety and about 48(12\%) of them had medical check-up (see Table 1 below)

Frequency of factors associated with prevalence of intestinal parasites

Two hundred seventy four $/ 68.7 \%$ of the study samples were from restaurants and only $15.5 \%$ were from hotels. Among the samples, only $45.4 \%$ wore gown and only $36.8 \%$ wore cape. Sixty eight percent food and drinking establishments have functional water pipe, and $96 \%$ drinking and food establishments had latrine, (see table 2 below)

\section{Infection status}

Regarding infection status, $26.1 \%$ of the participants were found to be infected with intestinal parasites. The most prevalent species was Ascaris lumbricoid (7.3\%)followed by tricuriasis (4\%)whereas the least prevalent species was hook worm (see figure 2 below)

\section{Multivariate analysis}

The odd of infection is $48 \%$ less likely in the participants who served for more than 10 years compared to that of participants who served for less than 1year.The risk of infection among the study participants who wash their hands after food preparation is 1.37 times more likely to be infected compared to respondents who wash their hands routinely. Respondents who did not trim their fingers nails were 1.89 times more likely to be infected than that of the respondents who trimmed their finger nails. The risk of infection in Study participants who does not use common knife to cut raw meat and other foods were $43 \%$ times lower than those who use common knife.see table 3 below

\section{Discussion}

Several studies across the world have determined the prevalence of intestinal parasites among food handlers. HundaolGirma et al, revealed that ; the prevalence rates of the intestinal parasites infections among food-handlers in different part of the world range from $28.7 \%$ to $52.2 \%$ [12]. The prevalence of intestinal parasites among food handlers working in food and drink establishments at mizan-aman town was $26.1 \%$. This is nearly similar with the finding of (25\%) in Gonder University Ethiopia [6]. However it is higher than what was reported in northern Iran, the prevalence of intestinal parasites was 3.73\% [4]and in Axum, Ethiopia which was 14.5\%[5]. 
On the other hand, the result of this study was lower than a cross sectional study report in Bahir Dar town, in which 158 (41.1\%) of food handlers were found to be infected with intestinal parasites. [7]. Another similar study in Arbaminch University revealed that $36 \%$ of the study participants found to be infected with intestinal parasites[8] and a study conducted in Jimma Zone, Yebu town reported highest rate of intestinal parasite 44.1\%[9].The differences might be due to differences in climate, geographical location, socio-demographic features of the populations.

The predominant parasite identified from the stool specimens in this study was positive for Ascaris lumbricoides 29(7.3\%), followed by Taniasis 20(5\%) and Entamoeba histolytica 14(3.5\%). This was inconsistent with the finding of a similar study conducted in Gondar University , Giardia lamblia was the most prevalent parasites 22(11\%), followed by Ascaris lumbricoides 13(6.5\%) and Entamoeba histolytica12(6\%)[6].

According to our research finding, the odd of infection is $48 \%$ less likely in the participants who served for more than 10 years compared to that of participants who served for less than 1year. But, according to the research done in southern part of Ethiopia, there was no association between year of service and prevalence of parasitic infection (8). The risk of infection among the study participants who wash their hands only after food preparation is 1.37 times more likely to be infected compared to respondents who wash their hands routinely. The habit of hand washing practice was similarly associated with infection rate according to research conducted in Arbamich (8). Respondents who did not trim their fingers were 1.89 times more likely to be infected than that of the respondents who trimmed their fingers. This finding was similar with that of Arbaminch according to the report; parasitic infection rate was 2 times higher among the participants who didn't trim their finger nails. The risk of infection in Study participants who does not use common knife to cut raw meat and other foods were $43 \%$ times lower than those who use common knife. This study finding was in contrary with that of Arbaminch town, according to the report, the odds of infection in the participants who use common knife to cut raw meat and other foods was $72 \%$ times lower compared to that of not use common knife.(8)

\section{Conclusion}

The prevalence of intestinal parasite in Mizan Aman city food and drinking establishment is $26.1 \%$.and work experience, finger trimming status, and using common knife for cutting raw meat and other foods were factors associated with the parasitic infections.

\section{Abbreviations}

CSA: Central Statistics Agency

E.C : Ethiopian Calendar

MAHSC: Mizan Aman Health Science College

SNNPR: South Nation Nationalities People Region

SPSS: Statistical Package for Social Science

WHO: World Health Organization

\section{Declarations}

\section{Ethics approval and consent to participate}

This research was conducted after getting approval from Mizan Aman Health Science College research and publication office. Permission was obtained from Mizan Aman town Trade and Industry Office. During data collection the aim of the 
study was communicated to the respondents and the food \& drink establishment owners after signing on the consent form

\section{Consent for publication}

The finding of this study was presented to Mizan Aman Health Science College. The copies of the finding were given to Trade and Industry Office.Moreover, attempts will be made to publish reputable international journals.

\section{Availability of data and materials}

The data that support the findings of this study is available at the hands of Mr. AM, the corresponding author and it can be delivered to the journal based on request at any time.

\section{Competing interests}

The authors declare that they have no competing interests.

\section{Funding}

The research was funded by Mizan Aman health science collage. The funders did not participated in any other activities

\section{Authors' contributions}

All authors participated in the design and analysis of the study. All researchers participated in revising and interpreting.

\section{ACKNOWLEDGEMENT}

First of all our special thanks go to God for his mercy for everything he has provided for us and his allowing finishing our works

Next we would like to thank Mizan Aman Health Science College for providing budget and other materials to successfully conduct our research and our gratitude go to Mizan Aman town Trade and Industry Office for their collaboration by giving the necessary support

we also want to appreciate the study participants and data collectors,

Finally we are happy to appreciate research square for announcing our work online.

\section{References}

1. BALUKA, S.A., R. MILLER, and J.B. KANEENE, Hygiene practices and food contamination in managed food service facilities in Uganda. African Journal of food science, 2015. 9(1): p. 31-42.

2. Mama, M. and G. Alemu, Prevalence and factors associated with intestinal parasitic infections among food handlers of Southern Ethiopia: cross sectional study.BMC public health, 2015.16(1): p. 105.

3. Mekasha, T., S. Neela, and D. Kumela, Food safety knowledge, practice and attitude of food handlers in traditional hotels of Jimma Town, Southern Ethiopia.Annals Food Science and Technology, 2016.17(2): p. 507-517.

4. Williams, J., District laboratory practice in tropical countries. Part 1: Monica Cheesbrough. Doddington, Cambridgeshire: Tropical Health Technology, 1998. viii+ 456pp. Pricef 10.90 (surface post) orf 19.00 (airmail). ISBN 9507434-4-5 [Also available from Cambridge University Press ( $£$ 35.00; ISBN 0-521-66547-7)], 2000, No longer published by Elsevier.

5. Malakotian, M., M. Hosseini, and H. Bahrami, Survey of the parasires of vegetable in Kerman province.Medical Journal of Hormozgan University, 2009.13(1): p. 55-62. 
6. Kulkumthorn, M. and S. Nuchprayoon, The prevalence of intestinal parasitic infections among school children in the central region of Thailand.J Med Assoc Thai, 2006.89(11): p. 1928-33.

7. Pandey, S., A.L. Lo, and R.B. Shrestha, Intestinal parasitic infections among school children of Northern Kathmandu, Nepal.Asian Pacific Journal of Tropical Disease, 2015.5: p. S89-S92.

8. Alum, A., J.R. Rubino, and M.K. ljaz, The global war against intestinal parasites-should we use a holistic approach? International Journal of Infectious Diseases, 2010.14(9): p. e732-e738.

9. Ridley, J.W., Parasitology for medical and clinical laboratory professionals2012: Cengage Learning.

10. Assefa, T., et al., Contamination of bacteria and associated factors among food handlers working in the student cafeterias of Jimma University Main Campus, Jimma, South West Ethiopia.Alternative \& Integrative Medicine, 2015.

11. Soleimnanpoor, H., A. Zohor, and A. Ebrahimzadeh, The survey of parasitic contamination of vegetables in Zabol city during 2011-2012.Zabol University of Medical Sciences, 2013.3(2): p. 40-47.

12. Tefera, T. and G. Mebrie, Prevalence and predictors of intestinal parasites among food handlers in Yebu town, southwest Ethiopia.PLoS One, 2014.9(10): p. e110621.

13. Wegayehu, T., et al., Prevalence of intestinal parasitic infections among highland and lowland dwellers in Gamo area, South Ethiopia.BMC public health, 2013.13(1): p. 151.

14. Deribe, K., et al., The burden of neglected tropical diseases in Ethiopia, and opportunities for integrated control and elimination.Parasites \& vectors, 2012.5(1): p. 240.

15. Ifeadike, C.O., et al., Assessment of the food hygiene practices of food handlers in the Federal Capital Territory of Nigeria.Tropical journal of medical research, 2014.17(1): p. 10.

16. Kumie, A., et al., The sanitary condition of food and drink establisment in Awash-Sebat Kilo town, Afar region, Ethiopia.Ethiopian Journal of Health Development, 2006.20(3).

17. Gezehegn, D., et al., Prevalence and factors associated with intestinal parasites among food handlers of food and drinking establishments in Aksum Town, Northern Ethiopia.BMC public health, 2017.17(1): p. 819.

18. Tessema, A.G., K.A. Gelaye, and D.H. Chercos, Factors affecting food handling Practices among food handlers of Dangila town food and drink establishments, North West Ethiopia.BMC public health, 2014.14(1): p. 571.

19. Mudey, A.B., et al., Health status and personal hygiene among food handlers working at food establishment around a rural teaching hospital in Wardha District of Maharashtra, India.Global Journal of Health Science, 2010.2(2): p. 198.

20. Salary, S., Prevalence of intestinal parasite infestation in the food suppliers of Kerman City, Iran, in 2010.Journal of Health and Development, 2013.1(4): p. 315-322.

21. Meleko, A., et al., Assessment of the sanitary conditions of catering establishments and food safety knowledge and practices of food handlers in Addis Ababa University Students' Cafeteria.Science, 2015.3(5): p. 733-743.

22. Pullan, R.L., et al., Global numbers of infection and disease burden of soil transmitted helminth infections in 2010.Parasites \& vectors, 2014.7(1): p. 37.

23. Sharif, L., M.M. Obaidat, and M.-R. Al-Dalalah, Food hygiene knowledge, attitudes and practices of the food handlers in the military hospitals.Food and Nutrition Sciences, 2013.4(03): p. 245.

24. www.researchsquare.com

\section{Tables}

Table 1. Sociodemographic characteristics and factors associated with prevalence of intestinal parasites among food handlers in Mizan Aman town, 2017 


\begin{tabular}{|c|c|c|c|c|c|}
\hline \multicolumn{2}{|c|}{\begin{tabular}{|l} 
Variable \\
\end{tabular}} & Frequency & Percent & \multicolumn{2}{|c|}{ Parasitic infection } \\
\hline \multirow[t]{6}{*}{ Age of the respondents } & & & & & \\
\hline & $<20$ & 194 & 48.6 & $55(13.7 \%)$ & $139(34.8 \%)$ \\
\hline & $20-35$ & 170 & 42.6 & $38(9.52 \%)$ & $132(33.08)$ \\
\hline & $36-50$ & 11 & 2.8 & $4(1.00 \%)$ & $7(1.75)$ \\
\hline & $51-65$ & 20 & 5.0 & $6(1.50 \%)$ & $14(3.50 \%)$ \\
\hline & $>65$ & 4 & 1.0 & $1(0.25 \%)$ & $3(0.75 \%)$ \\
\hline \multirow[t]{2}{*}{ Sex of the respondents } & Female & 203 & 50.9 & $50(14.0 \%)$ & $153(38.3 \%)$ \\
\hline & Male & 196 & 49.1 & $54(12.1 \%)$ & $142(35.5 \%)$ \\
\hline \multirow{5}{*}{$\begin{array}{l}\text { Educational status of the } \\
\text { respondents }\end{array}$} & university & 16 & 4.0 & $5(1.25 \%)$ & $11(2.75 \%)$ \\
\hline & collage & 29 & 7.3 & $12(3.00 \%)$ & $17(4.26 \%)$ \\
\hline & high school & 94 & 23.6 & $25(6.26 \%)$ & $69(17.29 \%)$ \\
\hline & Primary school & 217 & 54.4 & $52(13.03 \%)$ & $165(41.35 \%)$ \\
\hline & Cannot read and write & 43 & 10.8 & $10(2.50 \%)$ & $33(8.27 \%)$ \\
\hline \multirow{3}{*}{$\begin{array}{l}\text { Specific job of the } \\
\text { respondent in the } \\
\text { establishment }\end{array}$} & cooker & 110 & 27.6 & $39(9.77 \%)$ & $71(17.79 \%)$ \\
\hline & cleaner & 52 & 13.0 & $11(2.75 \%)$ & $41(10.27 \%)$ \\
\hline & waiter & 237 & 59.4 & $54(13.53 \%)$ & $183(45.86 \%)$ \\
\hline \multirow{4}{*}{$\begin{array}{l}\text { Experience of the } \\
\text { respondent }\end{array}$} & $<1$ year & 197 & 49.4 & $56(14.03 \%)$ & $141(35.33 \%)$ \\
\hline & $1-5$ years & 172 & 43.1 & $42(10.52 \%)$ & $130(32.58 \%)$ \\
\hline & 6 years-10years & 26 & 6.5 & $5(1.25 \%)$ & $21(5.26)$ \\
\hline & $>10$ years & 4 & 1.0 & $1(0.25 \%)$ & $3(0.75 \%)$ \\
\hline \multirow{3}{*}{$\begin{array}{l}\text { Training on food } \\
\text { preparation and hygiene }\end{array}$} & & & & & \\
\hline & yes & 27 & 6.8 & $9(2.25 \%)$ & $18(4.51 \%)$ \\
\hline & no & 372 & 93.2 & $95(23.80 \%)$ & $277(69.42 \%)$ \\
\hline
\end{tabular}

Table 2. Shows frequency of factors associated with prevalence of intestinal parasites among food handlers in Mizan Aman town, 2017 


\begin{tabular}{|c|c|c|c|c|c|}
\hline \multirow[t]{2}{*}{ Variable } & & \multirow[t]{2}{*}{ Frequency } & \multirow[t]{2}{*}{$\%$} & \multicolumn{2}{|c|}{ Parasitic infection } \\
\hline & & & & Infected & Not infected \\
\hline \multirow[t]{3}{*}{ Number of participants in establishments } & Restaurant & 274 & 68.7 & 79(19.7\%) & $195(48.8 \%)$ \\
\hline & Drinking & 63 & 15.8 & $6(1.5 \%)$ & $57(14.28 \%)$ \\
\hline & Hotel & 62 & 15.5 & $19(4.76 \%)$ & $43(10.77 \%)$ \\
\hline \multirow[t]{2}{*}{ Does the respondent wear gown? } & Yes & 181 & 45.4 & $52(13.03 \%)$ & $129(32.33 \%)$ \\
\hline & No & 218 & 54.6 & $52(13.03 \%)$ & $166(41.60 \%)$ \\
\hline \multirow[t]{2}{*}{ Does the respondent wear hair net/ cape? } & Yes & 147 & 36.8 & $48(12 \%)$ & $99(24.8 \%)$ \\
\hline & No & 252 & 63.2 & $56(14.03 \%)$ & $196(49.12 \%)$ \\
\hline \multirow[t]{2}{*}{ Does the food handler touch food with bare hand? } & Yes & 152 & 38.1 & $52(13.0 \%)$ & $100(25.06 \%)$ \\
\hline & No & 247 & 61.9 & $52(13.0 \%)$ & $195(48.8 \%)$ \\
\hline \multirow[t]{2}{*}{ Does the respondent wear hand jewelry? } & Yes & 143 & 35.8 & $40(10.02 \%)$ & $103(25.8 \%)$ \\
\hline & No & 256 & 64.2 & $64(16.04 \%)$ & 192(48.1\%) \\
\hline \multirow[t]{2}{*}{ Does the respondent trim his/her finger nail? } & Yes & 227 & 56.9 & $52(13.0 \%)$ & $175(43.8 \%)$ \\
\hline & No & 172 & 43.1 & $52(13.0 \%)$ & $120(30 \%)$ \\
\hline \multirow{2}{*}{$\begin{array}{l}\text { Do you prepare food while suffering from disease } \\
\text { like diarrhea, cold or skin diseases }\end{array}$} & Yes & 73 & 18.3 & $25(6.2 \%)$ & $48(12 \%)$ \\
\hline & No & 326 & 81.7 & 79(19.7\%) & $247(72.8 \%)$ \\
\hline \multirow[t]{2}{*}{ Is there functional pipe water? } & Yes & 142 & 68 & & \\
\hline & No & 67 & 32 & & \\
\hline \multirow[t]{2}{*}{ Is there three dish washing compartments? } & Yes & 131 & 62.7 & & \\
\hline & No & 78 & 37.3 & & \\
\hline \multirow[t]{2}{*}{ Is there soap at the hand washing area? } & Yes & 118 & 56.4 & & \\
\hline & No & 91 & 43.6 & & \\
\hline \multirow[t]{2}{*}{ Is there latrine? } & Yes & 200 & 96 & & \\
\hline & No & 9 & 4.0 & & \\
\hline \multirow[t]{2}{*}{ Do you make health examination every 6 months? } & Yes & 48 & 12 & $12(3.0 \%)$ & $36(9.02 \%)$ \\
\hline & No & 351 & 88 & $92(23.05 \%)$ & \\
\hline
\end{tabular}

Table 3: Factors associated with prevalence of intestinal parasites among food handlers in Mizan Aman town, 2017 


\begin{tabular}{|c|c|c|c|c|c|c|}
\hline \multirow[t]{3}{*}{ Variables } & & \multicolumn{2}{|c|}{ Infection status } & \multirow[t]{3}{*}{ COR $(95 \% \mathrm{Cl})$} & \multirow[t]{3}{*}{ AOR $(95 \% \mathrm{Cl})$} & \multirow{3}{*}{$\begin{array}{l}P \\
\text { value }\end{array}$} \\
\hline & & Yes & $\mathrm{No}(\mathrm{N}(\%)$ & & & \\
\hline & & $N(\%)$ & & & & \\
\hline \multirow[t]{5}{*}{ Age } & $<20$ & $55(28.35)$ & 139(77.65) & 1 & 1 & \\
\hline & $20-35$ & $38(22.4)$ & 132(77.6) & 1.74(.053,2.215) & $1.210(0.123,3.741)$ & 0.989 \\
\hline & $36-50$ & $4(36.6)$ & $7(63.4)$ & $.192(1.195,2.460) \star \star$ & $2.67(0.723,3.12)$ & 0.712 \\
\hline & $51-65$ & $6(30)$ & $14(70)$ & $.923(.338,2.525)$ & $0.915(0.122,6.367)$ & 0.344 \\
\hline & $>65$ & $1(25)$ & $3(75)$ & 1.187(.121,11.659) & $4.21(0.983,2.111)$ & 0.812 \\
\hline \multirow{5}{*}{$\begin{array}{l}\text { Education } \\
\text { status of } \\
\text { the } \\
\text { respondent }\end{array}$} & University & $5(29.4)$ & 11(70.6) & $.667(.187,2.379)$ & $1.500(.420,5.325)$ & 0.532 \\
\hline & Collage & $12(41.1)$ & $17(58.9)$ & $0.429(.154,1.194)$ & $2.329(.837,6480$ & 0.125 \\
\hline & Highschool & $25(26.6)$ & $69(73.4)$ & $.678(0.836, .360)$ & & 0.678 \\
\hline & Primary school & $52(24)$ & 165(76) & $.021(.962, .444) * \star$ & $0.76(0.835,2.712)$ & 0.134 \\
\hline & Cannot readandwrite & $10(23.3)$ & $33(76.7)$ & 1 & 1 & \\
\hline \multirow{4}{*}{$\begin{array}{l}\text { Working } \\
\text { experience }\end{array}$} & $<1 \mathrm{yr}$ & $56(28.4)$ & 141(71.6) & 1 & 1 & \\
\hline & $1-5 y r$ & $42(24.4)$ & 131(75.6) & $1.45(0.23,0.897) \star \star$ & 2.12(0.478.7.123) & 0.347 \\
\hline & $6-10 y r$ & $5(19.2)$ & 21(70.8) & & & \\
\hline & $>10 y r$ & $1(25)$ & $3(75)$ & $2.49(0.09,0888)$ & $0.52(2.430,5.012) * *$ & 0.019 \\
\hline \multirow{5}{*}{$\begin{array}{l}\text { When do } \\
\text { you wash } \\
\text { your } \\
\text { hands? }\end{array}$} & $\begin{array}{l}\text { Before food } \\
\text { preparation }\end{array}$ & $7(26.9)$ & 19(73.1) & $0.99(0.39,2.46)$ & $0.56(0.19,1.6)$ & 0.273 \\
\hline & $\begin{array}{l}\text { Before equipment } \\
\text { washing }\end{array}$ & $12(42.8)$ & $16(57.2)$ & $0.49(0.21,1.08)$ & $1.67(0.63,4.41)$ & 0.305 \\
\hline & After toilet visit & $13(27.1)$ & $35(76.9)$ & $0.98(0.49,1.97)$ & $0.82(0.36,1.88)$ & 0.633 \\
\hline & $\begin{array}{l}\text { After food } \\
\text { preparation }\end{array}$ & $9(14.7)$ & $52(85.3)$ & $2.1(0.98,4.52)$ & $1.37(0.15,0.9) * \star$ & 0.029 \\
\hline & Repeatedly/Routinely & $63(26.6)$ & 173(73.4) & 1 & 1 & \\
\hline \multirow{2}{*}{$\begin{array}{l}\text { Does the } \\
\text { respondent } \\
\text { trim } \\
\text { his/her } \\
\text { finger? }\end{array}$} & Yes & $52(29.7)$ & 175(70.3) & 1 & 1 & \\
\hline & No & $52(30.2)$ & $120(69.8)$ & $1.92(0.23,0.245)^{\star \star}$ & $1.89(1.01,3.960)^{\star \star}$ & 0.029 \\
\hline \multirow{2}{*}{$\begin{array}{l}\text { Do you use } \\
\text { common } \\
\text { knife for } \\
\text { cutting raw } \\
\text { meat and } \\
\text { other } \\
\text { foods? }\end{array}$} & Yes & $53(30.5)$ & $121(69.5)$ & 1 & 1 & \\
\hline & No & $51(22.7)$ & 174(77.3) & 7.89(0.78,3.129) & $0.57(3.61,5.54) * *$ & 0.001 \\
\hline
\end{tabular}

\section{Figures}




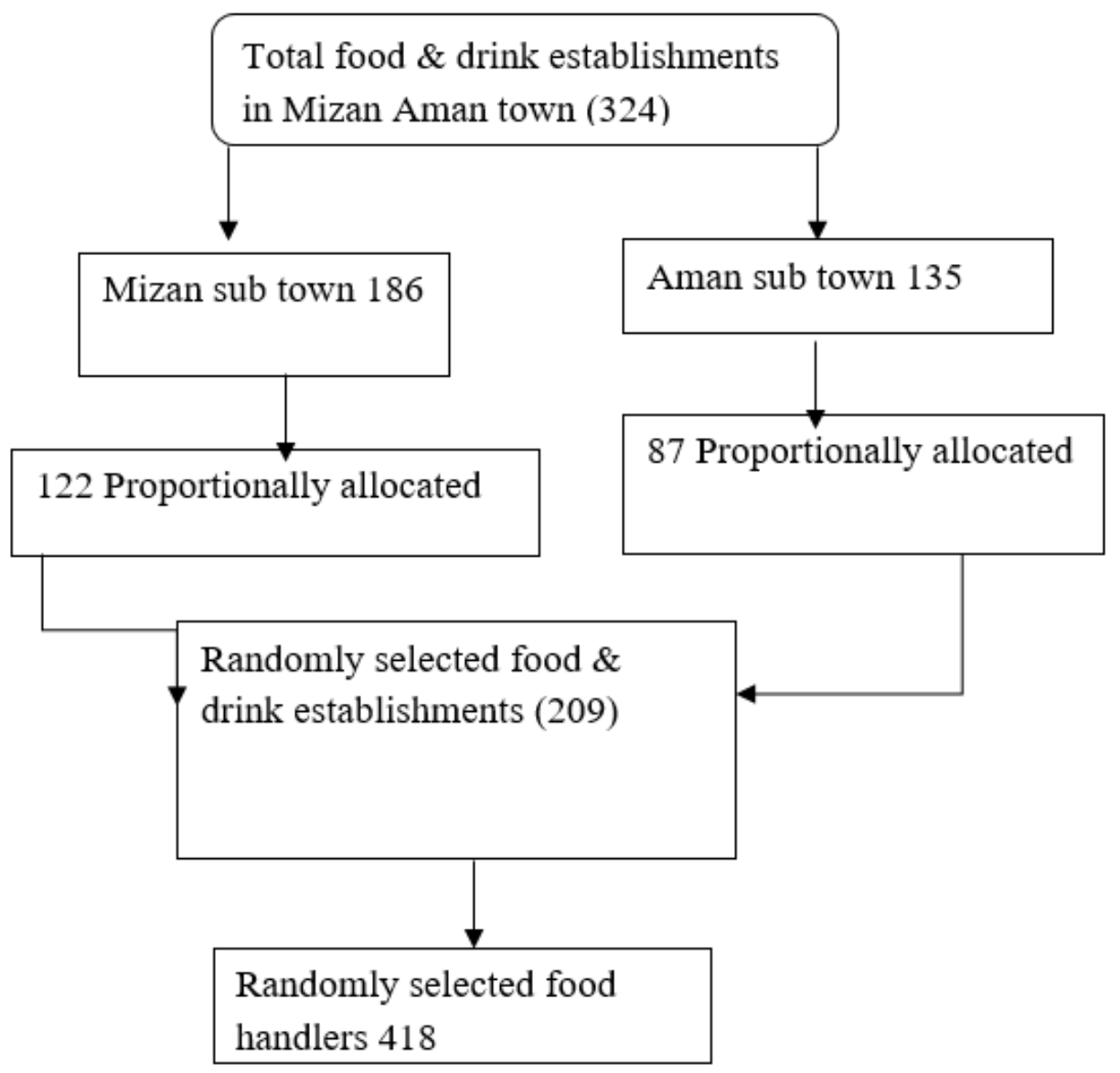

Figure 1

Sampling procedure

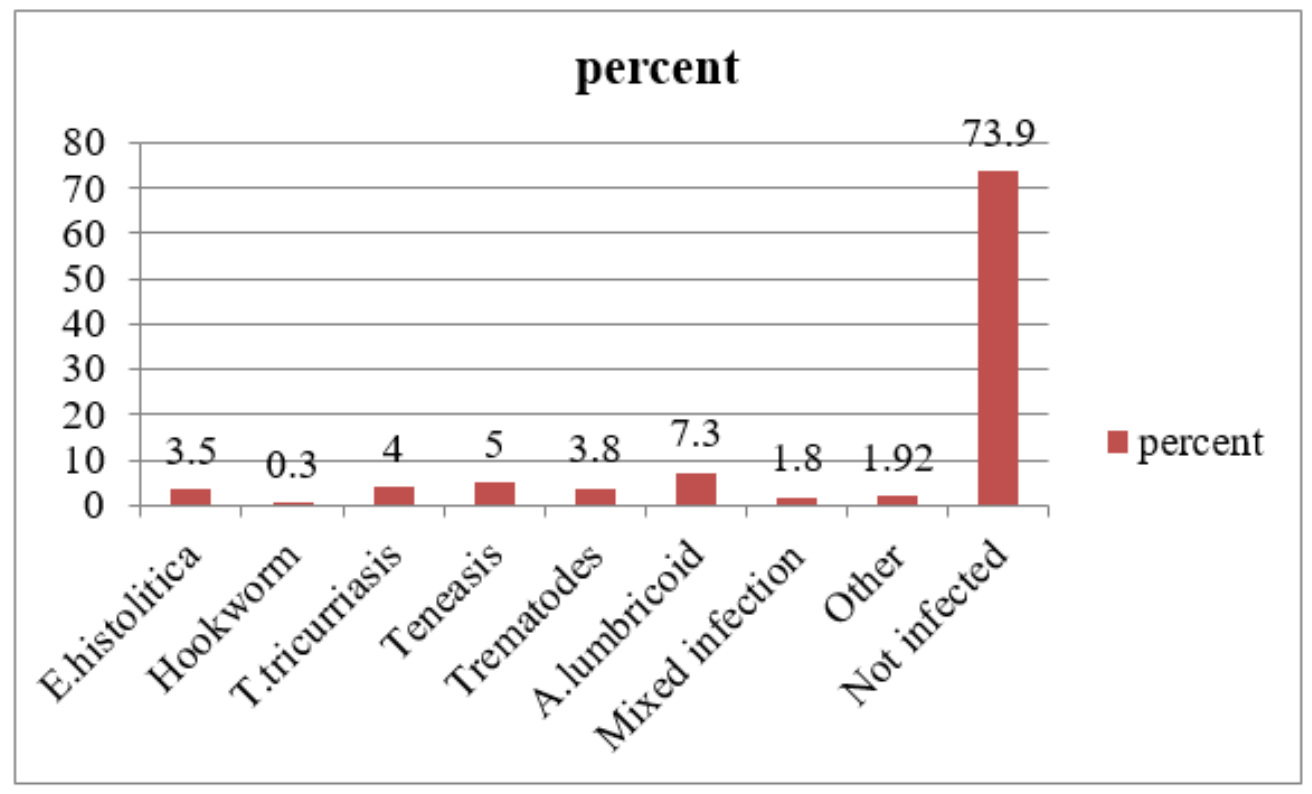

Figure 2

prevalence of species of parasitic infection among food handlers in Mizan Aman town in 2017 